\title{
Surface melting derived from microwave radiometers: a climatic indicator in Antarctica
}

\author{
G. PICARD, M. FILY, H. GALLEE \\ Laboratoire de Glaciologie et Géophysique de I'Environnement (CNRS-UJF), 54 rue Molière, \\ 38400 Saint-Martin-d'Hères Cedex, France \\ E-mail: ghislain.picard@lgge.obs.ujf-grenoble.fr
}

\begin{abstract}
This paper aims at presenting a new dataset including the melt events derived from microwave remote sensing occurring in Antarctica from summer 1979/80 to 2005/06. The method for detecting melt events and sources of error is presented, and then trends in melt duration for every pixel are extracted from the dataset, mapped and analyzed. The analysis focuses on two particular cases, and the main results show that: (1) the trends over the period 1980-2006 in the Antarctic Peninsula match with lengthening of the melt season on the ice shelves and, surprisingly, shortening of the melt season in the mountainous area of the peninsula; and (2) the trends over the period 1996-2006 on the entire continent show a dipolar pattern, with the western regions experiencing decreasing melt duration, whereas East Antarctica and the Ross Ice Shelf experience increasing melt duration. This pattern closely mirrors the temperature pattern expected when the Southern Annular Mode is in a decreasing trend, as it is over the period 1996-2006. For further analysis and validation, the dataset has been made available at http://www-Igge.obs.ujf-grenoble.fr/ picard/melting/.
\end{abstract}

\section{INTRODUCTION}

The spatial variability of the Antarctic climate remains largely unknown, partially due to the sparsity of the meteorological station network. These stations provide accurate measurements, often over long periods, that are particularly suitable for deriving long-term trends, but their coverage is insufficient to provide information about spatial variability (Turner and others, 2005). Some techniques exist for spatializing the information, such as data assimilation used in re-analysis of meteorological data (Uppala and others, 2005) or kriging (Arthern and others, 2006), but they rely on underlying physical or statistical models. It is not possible to retrieve meteorological variables by remote sensing with the same accuracy as ground stations, but remote sensing is a unique way to measure information about spatial variability over Antarctica.

Variables such as temperature, albedo and surface melting, which are of major interest for Antarctic climatology, can be retrieved by remote sensing. Among these climatic variables, surface melting is probably the easiest to detect accurately using passive microwave radiometers.

Radiometers measure the thermal energy emitted by the surface as well as the subsurface because microwaves penetrate the snow (typically $2 \mathrm{~m}$ at $19 \mathrm{GHz}$ ). This energy is proportional to the brightness temperature and depends on both the physical temperature and the emissivity. The presence of liquid water in the firn radically increases the absorption, and in turn the emissivity (Kirchoff's law). An increase in emissivity results in an increase in brightness temperature, which is efficiently and robustly detected by simple algorithms.

Microwave remote sensing is weakly influenced by the atmosphere even in cloudy conditions (except at some frequencies (e.g. 22 and $85 \mathrm{GHz}$ )). This is a crucial advantage over visible/infrared remote sensing for detecting individual melting events, especially in regions of Antarctica where melting occurs only a few days a year.
Another advantage of passive microwave remote sensing is the length (1979 onward) of the series. Surface melting can be retrieved over the entire period (with some limitations due to sensor replacement (Picard and Fily, 2006)), allowing trend analysis with high statistical confidence. Long time series are also important for the detection of oscillations in the trends.

In addition, the future of the series is ensured thanks to the operational Special Sensor Microwave/Imager (SSM/I) sensors (F13, F14, F15 and F16 operate currently) and the new enhanced radiometer AMSR-E (Advanced Microwave Scanning Radiometer for the Earth Observing System) aboard the Aqua platform.

Surface melting mainly occurs during summer on the coasts and ice shelves of Antarctica. The high central plateau never melts, as the temperature remains below the melting point all year round. As a consequence, surface melting provides climatic information about the summer season only and on a limited area of the continent $(25 \%$ of the continent has melted at least five times during the last 27 years and only $2 \%$ melts at least 1 day every year)

These limitations are counterbalanced by the numerous advantages cited above (series length, robust detection, etc.) that motivated new studies after the early works by Ridley (1993) and Zwally and Fiegles (1994). Torinesi and others (2003) took advantage of the length of the series (1979-99) to analyze cumulative melting surface (CMS) series (combination of the areal extent and duration of melting for entire regions) in terms of climatic trends and oscillations. They also showed that a significant correlation between melting and air temperature measured at meteorological stations exists but air temperature is not the only factor affecting surface melting. Fahnestock and others (2002) studied melt duration on the Antarctic Peninsula and showed that, on the ice shelves, the melt season lengthened over the period 1979-2000. This observation is one potential explanation for the break-up of the Larsen A and B ice shelves (Scambos and others, 2000). In Liu and others (2005) 

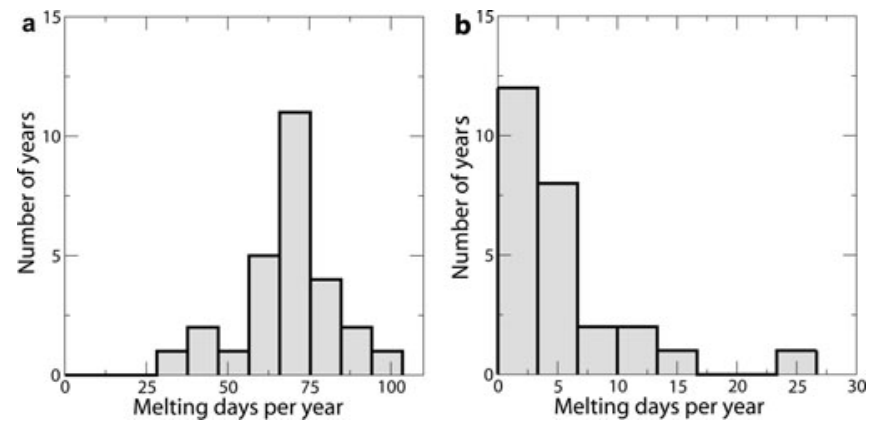

Fig. 1. Distribution of melt duration for two pixels: (a) a pixel with frequent melting in the peninsula; and (b) a pixel with rare melting in Dronning Maud Land.

a new and more efficient method is proposed to detect the melting events, and a rigorous evaluation of the accuracy is performed. The method is applied to the period 1978-2004, and CMS trends are analyzed as well as correlation with air temperature (Liu and others, 2006). In Picard and Fily (2006), we show that CMS series analyzed in Torinesi and others (2003) and Liu and others (2006) contain spurious trends due to satellite replacements. The brightness temperature series were acquired by four successive sensors (SMMR, SSM/I F8, F11 and F13) whose characteristics and orbits are slightly different. Sensors are on board heliosynchronous satellites which ensure almost constant local hours of observation over the satellite lifetime, but unfortunately the hours changed from one sensor to another. As melting intensity depends on the hour of the day, the change in observation hour contaminates the CMS time series. We quantified the phenomena and corrected the CMS series (Picard and Fily, 2006). The correction is substantial and changes significantly the melting trends calculated in Torinesi and others (2003).

Surface and subsurface melting has been modeled the Antarctic scale by Liston and Winther (2005) and compared to the passive microwave observations from Zwally and Fiegles (1994) and Torinesi and others (2003). The modeled CMS is about four times higher than Zwally and Fiegles' (1994) and Torinesi and others' (2003) observations and about 2.4 times higher than Liu and others' (2006) observations. The temporal variations are weaker than those observed by microwaves. These large differences (both between observations from different authors and between modeling and observations) suggest further validations are required.

In all these previous works, the relationship between climate change and surface melting is studied either at large scales (CMS trends in Torinesi and others, 2003; Liston and Winther, 2005; Liu and others, 2006) or for particular pixels (Fahnestock and others, 2002). In the present paper, we exploit the 'fine' resolution and the Antarctic-wide coverage of the dataset to analyze the spatial variability of Antarctic climate change.

\section{METHOD}

\subsection{Background and detection algorithm}

Time series of brightness temperature measured by microwave radiometers present very clear peaks throughout the summer in areas where melting occurs, especially at $19 \mathrm{GHz}$ in horizontal polarization (Zwally and Fiegles, 1994). We briefly explain the physical background for this phenomenon and its application to surface melting detection.

The brightness temperature $T_{\mathrm{b}}$ is the product of the emissivity $\varepsilon$ and the surface/subsurface physical temperature $T_{\mathrm{s}}$ :

$$
T_{\mathrm{b}}=\varepsilon T_{\mathrm{s}} .
$$

This equation is a first approximation and neglects atmospheric effects and snow penetration. However, for dry snow, emission originates from a layer extending from the surface down to a few meters deep (Sherjal and Fily, 1994).

Emissivity of dry snow is low, typically $0.65-0.80$ at $19 \mathrm{GHz}$ in horizontal polarization (Surdyk and Fily, 1995), because upwelling waves emitted by the lower layers are scattered by the upper layers and become trapped by the medium. When snow melts at or near the surface, the presence of liquid water increases the absorption. The emissivity increases to about 0.9 , resulting in an increase in brightness temperature by about $40 \mathrm{~K}$ (physical temperature is around the melting point). This amplitude is large and cannot be caused by seasonal variations of the physical temperature (Zwally and Fiegles, 1994; Cagnati and others, 2004). Therefore, detecting such a clear signature in the signal can be performed by a simple algorithm using a threshold: a pixel is classified as melted if $T_{\mathrm{b}}$ is above a fixed or adaptive threshold $T_{\text {bo }}$.

In practice, however, difficulties arise. The resolution of space-borne microwave radiometers is coarse, a few tens of kilometers at $19 \mathrm{GHz}$. When a pixel is partially melted, the increase in $T_{\mathrm{b}}$ is lower than $40 \mathrm{~K}$. Detecting such weak events requires a low threshold that in turn increases the risk of confusion between an increase really due to melting and an increase of the physical temperature (see Equation (1)). The solution adopted in our algorithm consists in using an adaptive threshold. The threshold is different for each pixel and depends on the winter brightness temperature mean and standard deviation (see Torinesi and others, 2003) so that only an increase in $T_{\mathrm{b}}$ well above the typical local seasonal variations is classified 'melted'. The algorithm settings ensure a good compromise between detecting weak events and avoiding false alarms (unmelted pixels detected as melted). Also, in some particular conditions, refreezing creates thick ice layers. These ice layers do not transmit upwelling waves emitted by the lower layer. The emissivity is then reduced with respect to the previous season (Abdalati and Steffen, 1998). During the following summer, the emissivity is still lower than usual, and peaks in $T_{\mathrm{b}}$ caused by melting are then lower than usual. They may be missed by the algorithm using a constant threshold as in Zwally and Fiegles (1994). Our algorithm deals with this issue by adapting the threshold every year.

A detection technique based on wavelet transforms has recently been proposed (Liu and others, 2005), but no extended inter-comparison has yet been performed. At this point, we note that the sensitivity/robustness balance is different between the two algorithms. Large differences in the number of detected melting events are observed, but the variations and trends are similar (see, e.g., CMS in the peninsula in Picard and Fily (2006) and Liu and others (2006)).

It is worth noting that detection of surface melting in Greenland uses a different approach: it uses a ratio of brightness temperatures at different frequencies (37 and $19 \mathrm{GHz}$ instead of $19 \mathrm{GHz}$ only) (Abdalati and Steffen, 1997) rather than a single brightness temperature. A recent study 
shows that using two frequencies allows melt detection but also distinguishes between different stages in the melting/ refreezing cycle (Ashcraft and Long, 2005). A drawback, however, concerns the brightness temperature sensitivity to precipitation at high frequency $(37 \mathrm{GHz})$ which causes bias in the melting series (Fettweis and others, 2005, 2006).

\subsection{Melting indices}

Our algorithm classifies each pixel on the continent, every day since 1979, as melted or not melted. It produces a huge amount of information that needs to be reduced before analysis. Various 'melting indices' have been proposed in different studies including:

1. for individual pixels: melt-onset and melt-end dates and melt-season duration (number of days with melting per year or month) (Zwally and Fiegles, 1994; Liu and others, 2005). The results are shown as maps

2. for entire regions: CMS measures the number of days $\times$ $\mathrm{km}^{2}$ melted in a region for a year or a month; mean melting day (MMD) (Zwally and Fiegles, 1994) measures the melt duration average for a region; and the maximum melting surface (MMS) measures the surface of all the pixels melting at least 1 day (Torinesi and others, 2003). These indices are usually shown as annual series.

Regions of Antarctica were defined by Zwally and Fiegles (1994) and have been reused almost 'as is' in Torinesi and others (2003), Liu and others (2006) and Picard and Fily (2006).

The annual CMS integrates both spatial and temporal information. It has been analyzed in recent studies (Liu and others, 2006; Picard and Fily, 2006). In the present paper, we focus on the spatial variability and analyze melt-season duration on a pixel basis.

\subsection{Satellite change issues}

In Picard and Fily (2006) we showed that the change of observation hours between the different satellites used for composing the 27 year long series has a significant impact on the CMS index time series. We proposed a correction method that specifically applies to the CMS index.

Change of observation hours also affects the melt duration, but no correction method exists yet. The method developed for the CMS cannot be easily applied for melt duration, as it requires statistics of melt duration that are not accurately estimable on a pixel basis. In the present paper, no correction is applied but our analysis takes this effect into account by noting that the hours of observation have been less and less favorable to melt detection from the SMMR (1979-88) up to the current SSM/I F13. As a consequence, a pixel experiencing no climatic change would have a slightly negative trend in melt duration, due to the satellite replacements (Picard and Fily, 2006). As a corollary, observed melt duration trends are negatively biased.

\subsection{Trends, correlation analysis and statistical issues}

The melting signal provides non-continuous information about climate as opposed to temperature for example. There are two reasons:

1. surface melting occurs when the temperature reaches the limit of $0^{\circ} \mathrm{C}$. Below this temperature, no quantitative information is carried in the melting signal

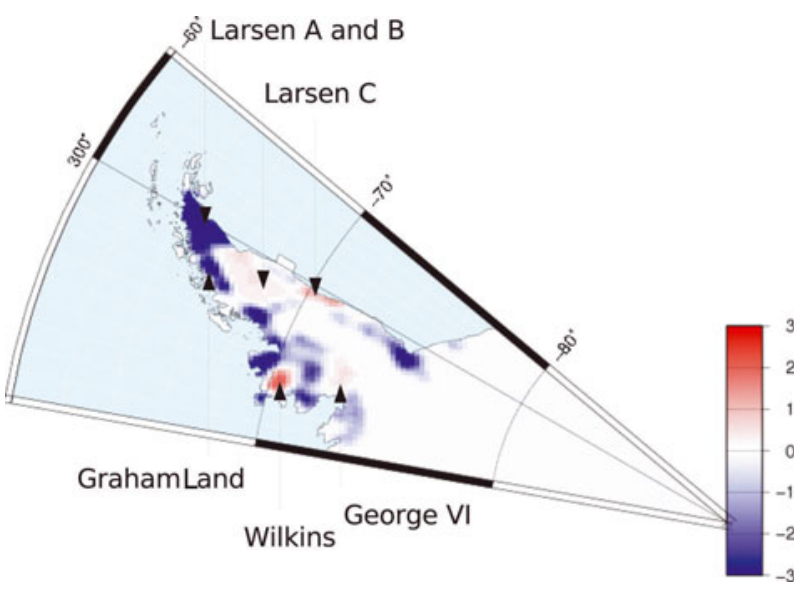

Fig. 2. Trends of melt duration on the peninsula over the summer $1979 / 80$ to summer 2005/06 period. Unit is per cent of change per year.

2. at $0^{\circ} \mathrm{C}$, the liquid-water content is a continuous variable, as the temperature is. Although liquid-water content is a variable of interest for climatology, it cannot currently be retrieved by microwave remote sensing.

Trend analysis (i.e. the least-squared optimization, interpreting the correlation value or Student test result) needs to be carefully conducted.

Where melting occurs frequently, the number of melting events is high and the melt duration behaves as a continuous variable. The distribution of melt duration is then approximately Gaussian (see Fig. 1a) and the usual trend analysis can be used. In contrast, where melting is rare, the distribution looks like an exponential (Fig. 1b), with many years experiencing no melting. In this case a trend analysis is less robust.

To deal with this issue, we retain the pixels where melting occurs at least 1 day over 20 or more years (for the 27 years of the series) and reject the other pixels. The selected area covers $1.0 \times 10^{6} \mathrm{~km}^{2}$ ( $8 \%$ of the continent). By comparison, regions melting at least 1 day every year cover only $0.3 \times$ $10^{6} \mathrm{~km}^{2}(2 \%)$, although regions melting 5 or more years cover about $3.3 \times 10^{6} \mathrm{~km}^{2}(25 \%)$.

\section{CLIMATIC TRENDS}

\subsection{Long-term trends on the peninsula}

Figure 2 shows a map of melt-duration trends for the full time series 1980-2006. Trends are expressed in per cent of annual variation and calculated by the following procedure: (1) a least-squares linear regression is performed on the meltseason duration time series $m d(t)$ :

$$
m d(t)=a t+b,
$$

where $t$ is the time in years; (2) the coefficient of linearity $a$ is normalized by the mean melt duration:

$$
\text { trend }=\frac{a}{\overline{m d(t)}} \text {. }
$$

The normalization is required to deal with the large dynamic range in melt duration (0-120 days $\mathrm{a}^{-1}$ ). 
Melting trends on the peninsula are contrasted, with mountains and ice shelves behaving oppositely. The following features are observed:

melt duration has been increasing on the ice shelves on both the western (Wilkins and George VI Ice Shelves) and eastern (Larsen $\mathrm{C}$ ice shelf) coasts. The changes are much larger on the Wilkins $\left(+2.7 \% \mathrm{a}^{-1}\right)$ than on the eastern coast or on the George VI (around $+1 \% \mathrm{a}^{-1}$ ). The Larsen A and B ice shelves (on the most northeasterly part of the peninsula coast) are a special case as they disintegrated between 1995 and 2002. As a consequence, no melting is detected in these regions anymore, so they appear in deep blue on the map. However, over the period 1980-2000 starting before the disintegration, melt duration on Larsen B is not decreasing and is rather steady. Fahnestock and others (2002) also reported a lengthening of the melt season for the Larsen B and C and Wilkins ice shelves over the period 1980-2000. The rates estimated from figure 5 in Fahnestock and others (2002) are similar to ours for the Wilkins $\left(+2.7 \% \mathrm{a}^{-1}\right.$ and $+2.5 \% \mathrm{a}^{-1}$, respectively) but are higher for the Larsen $\mathrm{B}$ $\left(+1.4 \% \mathrm{a}^{-1}\right.$ and steady, respectively) and the Larsen $\mathrm{C}$ $\left(+3.3 \% \mathrm{a}^{-1}\right.$ and $\left.1.0 \% \mathrm{a}^{-1}\right)$. These differences are most likely explained by the difference in the retrieval algorithms. Our algorithm is more adaptive as it uses year- and pixel-dependent thresholds on the brightness temperature, while Fahnestock and others (2002) used a fixed threshold

in contrast, melt duration has been significantly decreasing on the mountainous western coast from $64^{\circ} \mathrm{S}$ to $68^{\circ} \mathrm{S}$ (Graham Land) as well as on Alexander Island and on the eastern coast from $72^{\circ} \mathrm{S}$ to $76^{\circ} \mathrm{S}$. These observations are not reported in other studies. The negative bias caused by the satellite replacement contributes to these decreasing trends and, in principle, could be a slightly increasing trend in reality. However, this is excluded because the corrected CMS for the peninsula (Picard and Fily, 2006) is steady, meaning that melt duration has to decrease in some places in the peninsula to compensate the increasing trends observed on the ice shelves.

By only studying time series and trends of CMS, previous studies (Torinesi and others, 2003; Liu and others, 2006; Picard and Fily, 2006) gave an incomplete picture of melting evolution on the peninsula: CMS is nearly steady over the two decades. This observation apparently contradicts some facts: the warming observed at meteorological stations, and the ice-shelf disintegration and glacier surges (Cook and others, 2005). The new depiction provided by Figure 2 is clearer. The CMS is steady because of the compensation between opposite melt-duration trends in different areas.

The ice shelves are experiencing more and more melting, correlating with the warming observed by the meteorological stations, all located near the coasts or on islands (Comiso, 2000; Turner and others, 2005). Summer mean temperature (November-March) increased over the period 1980-2006 for most stations, for instance from north to south, by $+0.14^{\circ} \mathrm{C}_{\text {decade }}{ }^{-1}$ at $\mathrm{O}^{\prime}$ Higgins, $+0.18^{\circ} \mathrm{C}$ decade $^{-1}$ at Faraday $\left(65.4^{\circ} \mathrm{S}, 64.4^{\circ} \mathrm{W}\right)$ and $+0.27^{\circ} \mathrm{C}$ decade $^{-1}$ at Rothera. This also correlates with the disintegration of the shelves observed in the area (Scambos and others, 2000) and the positive trends observed by thermal infrared remote sensing on the open ocean (Comiso, 2000).
The shortening of the melt season on the mountainous western coast is a more surprising observation, as the closest meteorological stations record a warming (e.g. Faraday at $65.4^{\circ} \mathrm{S}$ ). Altitude and topography may be the key factors explaining this difference in trends. However, the upper-air temperatures measured (Reference Antarctic Data for Environmental Research (READER) project (Turner and others, 2005)) at the nearest station (Bellinghausen, located at the northernmost end of the peninsula) do not support this hypothesis, as they show strong warming in the summer at both $850 \mathrm{hPa}\left(+0.5^{\circ} \mathrm{C}\right.$ decade $\left.^{-1}\right)$ and $700 \mathrm{hPa}\left(+0.9^{\circ} \mathrm{C}\right.$ decade $\left.^{-1}\right)$. The only data correlating with the shortening are the pronounced cooling trend observed by thermal infrared $\left(-0.25^{\circ} \mathrm{Ca}^{-1}\right)$ in Graham Land (Comiso, 2000, fig. $17 \mathrm{~d}$ ).

In addition, surface melting changes are not necessarily explained by changes in temperature. Surface melting depends on all the terms of the surface energy balance. For instance, an increase of the mean albedo (perhaps due to more frequent snowfalls) reduces the shortwave radiation absorbed in the snow and thus reduces the energy available for melting. Also, melting can occur when air temperature is below $0^{\circ} \mathrm{C}$ if the incoming short waves are intense enough. In such conditions, an increase in wind speed increases the sensible flux toward the atmosphere which decreases the energy available for melting in the snow. This latter process may have compensated the warming observed at Faraday as the summer-mean wind speed at Faraday increased by as much as 25\% over the period 1979-2004 (data from the READER project (Turner and others, 2005)). More model studies are required to further interpret the complex relationship between trends in temperature and melt duration (e.g. Liston and Winther, 2005).

\subsection{Trends between summer $1995 / 96$ and summer 2005/06 in Antarctica}

The trend analysis presented here is limited to the last 11 summers (1996-2006). This period is chosen to avoid the artifacts caused by the satellite replacements. The SSM/I F13 has operated since 1995 and has the longest lifetime in the SSM/I family. Its observation hours have been fairly constant so that the trend derived from the limited series is more accurate than for any other periods.

Over such a short period, the trends are not representative of long-term changes, as the Antarctic climate is known to be influenced by several natural oscillations that operate on multi-decadal timescales, mainly the Southern Annular Mode (SAM) and the El Niño-Southern Oscillation (ENSO) (Genthon and Cosme, 2003). Therefore, the trend analysis presented here only represents a snapshot of the current variations.

Figure $3 a$ shows the melt-duration trends over the continent. The main feature is a clear east/west dipolar pattern: the melt season is shortening in the west (Antarctic Peninsula, Filchner Ice Shelf and eastern Dronning Maud Land) and lengthening in the east (East Antarctica and the Ross Ice Shelf). Both zones are homogeneous, with only a few spots having opposed trends.

Using a regional climate model, Van den Broeke and Lipzig (2004, fig. 5a) showed that summer near-surface temperature trends had a dipolar pattern when the SAM index was increasing (1980-93), with the peninsula warming and the rest of the continent cooling. For the period 1995-2005, the trend is reversed: the SAM was decreasing, with the probable consequence of a reversed dipolar pattern 

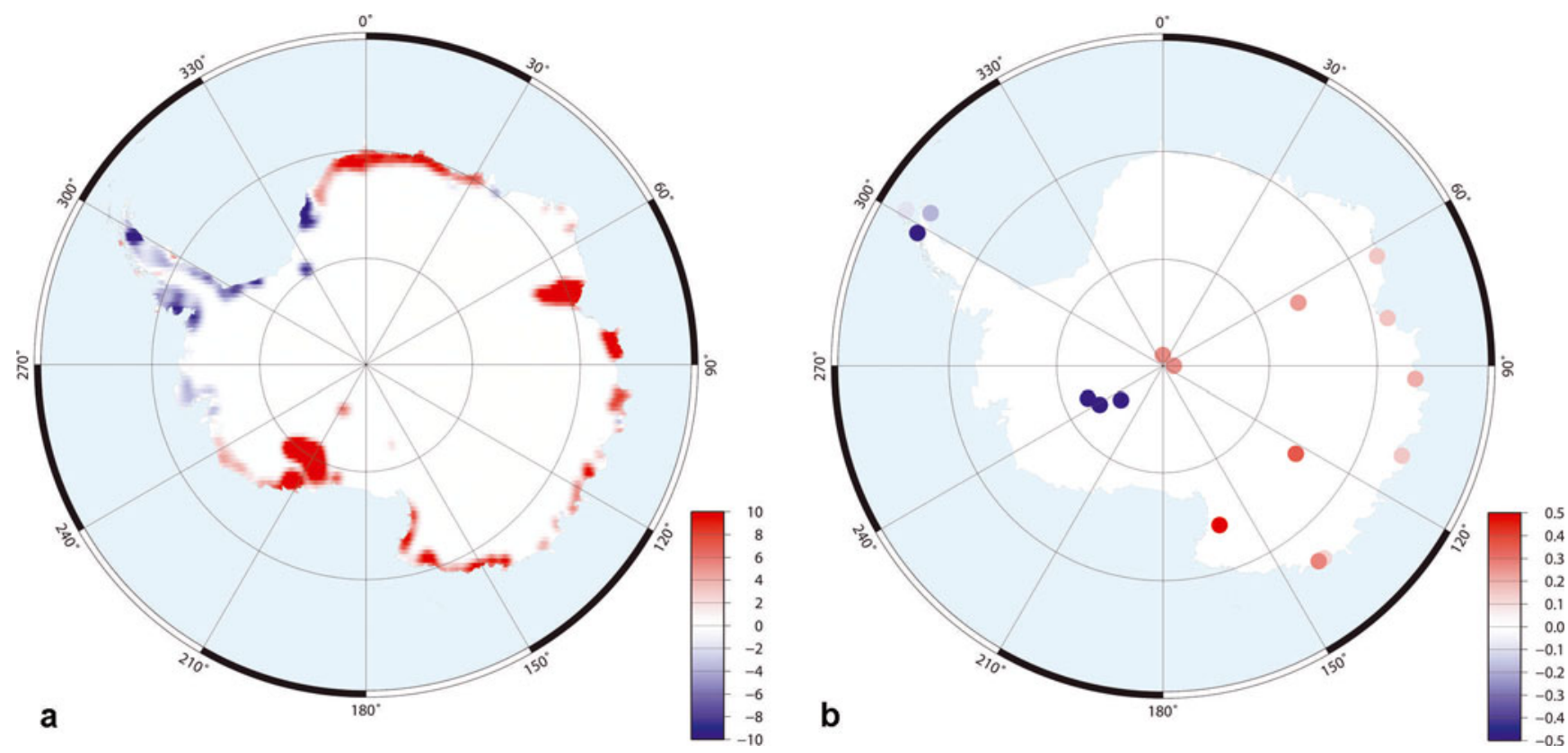

Fig. 3. (a) Trends in melt duration in Antarctica over the period 1995/96-2005/06. Unit is per cent of change per year. (b) Trends in measured air temperature (where $>90 \%$ confidence only). Unit is ${ }^{\circ} \mathrm{Ca}^{-1}$.

in the temperature trends, i.e. cooling on the peninsula and warming over the rest of the continent. This pattern closely mirrors our observed melt-duration trend and is confirmed in the air-temperature trend measured on the ground (READER project (Turner and others, 2005)) (Fig. 3b).

Over most of the peninsula, the melt season has been shortening over the last 11 years, although it was lengthening on the shelves over the last 27 years. This is in apparent contradiction to the disintegration of the Larsen B in 2002 (Larsen A disintegrated in 1995, at the beginning of the analyzed period) and the southward migration of glacier acceleration (Cook and others, 2005). The contradiction may be because the contribution of surface melting to iceshelf break-up or glacier surges is not obvious and probably acts on multiple timescales. Recent warming observed at stations over the past 50 years on the peninsula (Turner and others, 2005) and visible in the 27 year long trends of melt duration (section 3.1) may be the primary cause for the disintegration and surges. But at shorter timescales, surface melting is expected to be involved in the break-up as hypothesized by Scambos and others (2000) and Van den Broeke (2005). This mechanism involves intense surface melting, creation of melt ponds and the filling of crevasses which propagate within the shelf. This results in a weakening of the shelf that may lead to the break-up. Although our data agree on a long-term increase in melting, the melt duration in 2002 is not exceptionally long and the trend over the 11 years is not increasing.

A possible explanation is given by Van den Broeke (2005) who studied the energy budget in 2002 on the Larsen B ice shelves and noticed that the melt amount was much higher than in previous years (1995-2001), even if the melt duration was not significantly different. The timing of the melting days is important, as the solar energy varies during the summer. Another explanation lies in the chaotic dynamic of pond formation. This chaotic nature comes from the fact that free water (i.e. ponds) has a much lower albedo than a wet snow surface. The formation of ponds is thus controlled by a positive feedback: more melting $\rightarrow$ lower albedo $\rightarrow$ more absorbed energy $\rightarrow$ more melting. A slight change in the initial or meteorological conditions may result in one of two cases: a low-albedo surface with many growing ponds or a high-albedo surface with only wet snow. In both cases, microwave radiometers provide the same signal and may have missed the important pond formation in 2002 on the Larsen B. The retrieval of a quantitative value (such as the melt flux or the liquid-water content) from passive microwave is unlikely.

\section{CONCLUSION}

This paper mainly aims at presenting a new dataset, now available to the community. It is particularly interesting for further validations and analysis since:

1. it contains long and continuous temporal series with extensive and consistent spatial coverage. In the domain of remote sensing, 27 year long series are rare, and remote sensing is the only way to observe spatial variability over all of Antarctica

2. it will become longer each year. The availability of wellcalibrated passive microwave radiometer data is ensured for the future. Some improvements of the dataset could even be considered: for instance, the AMSR-E radiometer launched in 2002 offers twice the spatial resolution

3. the data are reliable, as melting events have a clear and easily detected signature in the microwave domain.

This dataset has, however, a few limitations that need to be accounted in the interpretation: (1) The algorithm provides a binary value (melted/not-melted), not a continuous value such as the liquid-water content. Statistical analysis therefore needs to be slightly adapted. (2) The dataset provides no climatic information inland, as no surface melting occurs there. (3) Changes in observation hours due to the satellite replacement are probably the most annoying issue for 
quantitative analysis: the four satellites used in the dataset cover the periods 1979-87, 1988-91, 1992-95 and 1996present respectively. Within these periods, no significant bias exists (the last period covers 11 years). However, dealing with the problem qualitatively is possible, as observation hours changed monotonically toward 'hours less favorable to melt observation' over the entire period. This means a positive trend in the melt duration is surely a real lengthening of the melt season (Picard and Fily, 2006). Future satellite replacements should not be as problematic as previously, because the current and future satellites will have a long overlap period.

Further information about the dataset and the technical issues is given on the distribution website at http://wwwIgge.obs.ujf-grenoble.fr/ picard/melting/.

\section{REFERENCES}

Abdalati, W. and K. Steffen. 1997. Snowmelt on the Greenland ice sheet as derived from passive microwave satellite data. J. Climate, 10(2), 165-175.

Abdalati, W. and K. Steffen. 1998. Accumulation and hoar effects on microwave emission on the Greenland ice-sheet dry-snow zones. J. Glaciol., 44(148), 523-531.

Arthern, R.J., D.P. Winebrenner and D.G. Vaughan. 2006. Antarctic snow accumulation mapped using polarization of $4.3-\mathrm{cm}$ wavelength microwave emission. J. Geophys. Res., 111(D6), D06107. (10.1029/2004JD005667.)

Ashcraft, I.S. and D.G. Long. 2005. Differentiation between melt and freeze stages of the melt cycle using SSM/I channel ratios. IEEE Trans. Geosci. Remote Sens., 43(6), 1317-1323.

Cagnati, A. and 7 others. 2004. Study of the snow melt-freeze cycle using multi-sensor data and snow modelling. J. Glaciol., 50(170), 419-426.

Comiso, J.C. 2000. Variability and trends in Antarctic surface temperatures from in situ and satellite infrared measurements. J. Climate, 13(10), 1674-1696.

Cook, A.J., A.J. Fox, D.G. Vaughan and J.G. Ferrigno. 2005. Retreating glacier fronts on the Antarctic Peninsula over the past half-century. Science, 308(5721), 541-544.

Fahnestock, M.A., W. Abdalati and C.A. Shuman. 2002. Long melt seasons on ice shelves of the Antarctic Peninsula: an analysis using satellite-based microwave emission measurements. Ann. Glaciol., 34, 127-133.

Fettweis, X., H. Gallée, F. Lefebre and J.P. van Ypersele. 2005. Greenland surface mass balance simulated by a regional climate model and comparison with satellite-derived data in 19901991. Climate Dyn., 24(6), 623-640.
Fettweis, X., H. Gallée, F. Lefebre and J.P. van Ypersele. 2006. The 1988-2003 Greenland ice sheet melt extent using passive microwave satellite data and a regional climate model. J. Climate, 27(5), 531-541.

Genthon, C. and E. Cosme. 2003. Intermittent signature of ENSO in west-Antarctic precipitation. Geophys. Res. Lett., 30(21), 2081. (10.1029/2003GL018280.)

Liston, G.E. and J.-G. Winther. 2005. Antarctic surface and subsurface snow and ice melt fluxes. J. Climate, 18(10), 1469-1481.

Liu, H., L. Wang and K. Jezek. 2005. Wavelet-transform based edge detection approach to derivation of snowmelt onset, end and duration from satellite passive microwave measurements. Int. J. Remote Sens., 26(21), 4639-4660.

Liu, H., L. Wang and K.C. Jezek. 2006. Spatiotemporal variations of snowmelt in Antarctica derived from satellite scanning multichannel microwave radiometer and Special Sensor Microwave Imager data (1978-2004). J. Geophys. Res., 111(F1), F01003. (10.1029/2005JF000318.)

Picard, G. and M. Fily. 2006. Surface melting observations in Antarctica by microwave radiometers: correcting 26-year time series from changes in acquisition hours. Remote Sens. Environ., 104(3), 325-336.

Ridley, J. 1993. Surface melting on Antarctic peninsula ice shelves detected by passive microwave sensors. Geophys. Res. Lett., 20(23), 2639-2642.

Scambos, T.A., C. Hulbe, M. Fahnestock and J. Bohlander. 2000. The link between climate warming and break-up of ice shelves in the Antarctic Peninsula. J. Glaciol., 46(154), 516-530.

Sherjal, I. and M. Fily. 1994. Temporal variations of microwave brightness temperatures over Antarctica. Ann. Glaciol., 20, 19-25.

Surdyk, S. and M. Fily. 1995. Results of a stratified snow emissivity model based on the wave approach: application to the Antarctic ice sheet. J. Geophys. Res., 100(C5), 8837-8848.

Torinesi, O., M. Fily and C. Genthon. 2003. Variability and trends of summer melt period of Antarctic ice margins since 1980 from microwave sensors. J. Climate, 16(7), 1047-1060.

Turner, J. and 8 others. 2005. Antarctic climate change during the last 50 years. Int. J. Climatol., 25(3), 279-294.

Uppala, S.M. and 45 others. 2005. The ERA-40 re-analysis. Q.J.R. Meteorol. Soc., 131(612), 2961-3211.

Van den Broeke, M. 2005. Strong surface melting preceded collapse of Antarctic Peninsula ice shelf. Geophys. Res. Lett., 32(12), L12815. (10.1029/2005GL023247.)

Van den Broeke, M.R. and N.P.M. van Lipzig. 2004. Changes in Antarctic temperature, wind and precipitation in response to the Antarctic Oscillation. Ann. Glaciol., 39, 119-126.

Zwally, H.J. and S. Fiegles. 1994. Extent and duration of Antarctic surface melting. J. Glaciol., 40(136), 463-476. 